\title{
Molecular characterization of the lactococcal plasmid pCIS3: natural stacking of specificity subunits of a type I restriction/modification system in a single lactococcal strain
}

\author{
Jos F. M. L. Seegers, ${ }^{1}$ Douwe van Sinderen ${ }^{2}$ and Gerald F. Fitzgerald ${ }^{1,2,3}$
}

Author for correspondence: Gerald F. Fitzgerald. Tel: +35321 902730. Fax: +35321903101. e-mail: g.fitzgerald@ucc.ie

National Food Biotechnology Centre', Department of Microbiology ${ }^{2}$, and Department of Food Science and Technology3, University College Cork, Cork, Ireland

\begin{abstract}
A 6.1 kb plasmid from the Lactococcus lactis subsp. cremoris strain UC509.9, named $\mathrm{pCIS3}$, was found to mediate a restriction/modification (R/M) phenotype. Nucleotide sequence analysis of pCIS3 revealed the presence of an hsdS gene, typical of type I R/M systems. The presence of this plasmid resulted in a $10^{4}$-fold reduction in the efficiency of plating (e.o.p.) of unmodified phage. In addition to the $h s d S$ gene of $\mathrm{pCIS3}$, two more $h s d S$ genes were identified in strain UC509.9, one located on the chromosome downstream of a gene highly homologous to hsdM genes and a third on the smallest (4 kb) plasmid, named pCIS1. The replication region of pCIS3 was highly similar to that of a large family of lactococcal theta replicons. In addition, pCIS3 was found to encode a member of the CorA family of magnesium transporters.
\end{abstract}

Keywords: Lactococcus lactis, restriction, modification, magnesium transport, cobalt resistance

\section{INTRODUCTION}

Lactococcal strains used in dairy fermentations are under continuous challenge by bacteriophages and, as a consequence, many strains have acquired several natural phage defence mechanisms. These are generally classified into four groups: (i) adsorption inhibition, (ii) injection blocking, (iii) abortive infection (abi) and (iv) restriction/modification ( $\mathrm{R} / \mathrm{M}$; for reviews see Garvey et al., 1995; Allison \& Klaenhammer, 1998). The first two mechanisms prevent the phage from entering the cell whilst mechanisms from the third group act on phage components after it has entered the cell. Adsorption inhibition is believed to be a result of the production of extracellular polymers such as polysaccharides that mask the phage receptor sites or, indeed, the complete absence of receptors. True injection blocking mechanisms where phage is capable of attaching to the cell but is unable to inject its DNA have been observed (Forde et al., 1999; Garvey et al., 1996), but to date none has been characterized at the molecular

Abbreviations: abi, abortive infection; $\mathrm{R} / \mathrm{M}$, restriction/modification.

The GenBank accession numbers for the sequences reported in this paper are AF153410-AF153414. level. Abi encompasses a broad range of phage defence mechanisms that prevent phage proliferation after infection. To date 17 different Abi mechanisms have been identified. Most of these appear to interact at the level of DNA and/or RNA metabolism (replication, transcription and translation). The fourth type of resistance mechanism, $\mathrm{R} / \mathrm{M}$ systems, is common in lactococci. These act on unmodified phage DNA as soon as it enters the cell whilst host DNA is protected from restriction by methylation at the cognate recognition sequence.

$\mathrm{R} / \mathrm{M}$ systems are classified into three groups, based on their molecular structure, sequence recognition, cleavage position and co-factor requirements. Representatives of all three groups have been found in lactococci. The most common are type II R/M systems. These generally consist of two separate enzymes, one responsible for restriction, the other for modification. They typically recognize a palindromic sequence of 4-8 nt and cut the DNA within this sequence. Several $\mathrm{R} / \mathrm{M}$ systems have been found that resemble the type II systems, but cut the DNA outside the recognition sequence. These have been subdivided as type IIs systems. A lactococcal example of a type IIs $\mathrm{R} / \mathrm{M}$ system is the LlaI system from the conjugative plasmid pTR2030 (O'Sullivan et al., 1995). This system also 
differs from other type II $\mathrm{R} / \mathrm{M}$ systems because the restriction activity is encoded by three genes rather than one. Several type II R/M systems have been identified in lactococcal strains. As is common for most phage resistance mechanisms, all of these, with the exception of the $S c r F I$ R/M system (Davis et al., 1993), were found to be plasmid located. Type III R/M systems consist of two subunits (Mod and Res) that form one functional holoenzyme with both restriction and modification activity. The enzyme recognizes specific asymmetric sequences and cuts the DNA at a fixed distance, 25-27 bp to one side of the recognition site. Recently, the first example of a lactococcal type III R/M system was identified and characterized (Su et al., 1999).

The most complex R/M systems are those of type I $\mathrm{R} / \mathrm{M}$. These consist of three subunits, named Hsd for host specificity determinant, that can form one holoenzyme. One subunit, HsdS, determines the nucleotide specificity of the holoenzyme. The second subunit, HsdM, is required for modification of the recognition sequence whilst the third, HsdR, is required for restriction activity. Methylation can occur only in the presence of HsdS and HsdM and does not require ATP. Restriction, however, requires the presence of all three subunits, as well as ATP, and occurs at non-specific sites that can be more than $1 \mathrm{~kb}$ from the recognition sequence (Yuan, 1981). HsdS subunits consist of two variable domains separated and flanked by highly conserved sequences. It was shown that the first variable domain specifies the $5^{\prime}$ DNA recognition sequence whereas the second specifies the 3' DNA recognition sequence, with a spacing of 6-8 nt between both (FullerPace \& Murray, 1986). As a consequence of their structure, variable domains can be swapped between the DNA regions encoding HsdS subunits via crossing-over events, resulting in novel $h s d S$ genes with altered specificities (Fuller-Pace \& Murray, 1986). Type I R/M systems have recently been shown to be widespread in lactococci and they could well be the most abundant $\mathrm{R} / \mathrm{M}$ systems present in this group of bacteria (Schouler et al., 1998a, b). Several of these systems are plasmid located and the subunits may be located on one plasmid or on different plasmids (Forde et al., 1999; Schouler et al., 1998b) whilst others are chromosomally located (Schouler et al., 1998b).

Lactococcus lactis subsp. cremoris UC509.9 is a prophage-cured derivative of strain UC509 which was originally isolated from a mixed starter culture (Arendt et al., 1994) and can be used as an indicator strain for the temperate phage Tuc2009. It harbours six cryptic plasmids, denoted pCIS1 to pCIS6. We found that phage propagated on a UC509.9 derivative which was cured of pCIS3 exhibited a $10^{4}$-fold reduction in the e.o.p. when used for the infection of L. lactis UC509.9 in the presence of pCIS3. Here, the entire nucleotide sequence of pCIS3 is reported. It was found to encode an $h s d S$ gene, typical of type I R/M systems. Two additional $h s d S$ genes were identified, one located on the chromosome and the other located on a $4 \mathrm{~kb}$ plasmid. The presence of multiple $h s d S$ genes in a single host provides great potential for genetic recombination between them with the consequential possibility of increasing phage resistance. Furthermore, an ORF was identified on pCIS3, which shows homology to a ubiquitous class of magnesium transporters, known as corA (Kehres et al., 1998).

\section{METHODS}

Strains, plasmids and phage. All strains, plasmids and phages used in this study are listed in Table 1. Plasmid pCIS3 was genetically marked with an erythromycin-resistance gene by replacing a PstI-SmaI fragment of pBIS3 with a PstI-SmaI fragment from pGKV210 (van der Vossen et al., 1987), resulting in pCIS31.1. As a consequence of this manipulation, the $\operatorname{cor} A$ gene was deleted.

Media and growth conditions. Escherichia coli strains were grown in Luria-Bertani medium (LB) at $37^{\circ} \mathrm{C}$ (Sambrook et al., 1989), supplemented with $100 \mu \mathrm{g}$ ampicillin $\mathrm{ml}^{-1}$ or $100 \mu \mathrm{g}$ erythromycin $\mathrm{ml}^{-1}$ when appropriate. L. lactis strains were grown at $30^{\circ} \mathrm{C}$ in GSB, a modified version of LSB which contains glucose instead of lactose (Arendt et al., 1994), or in M17 broth (Difco), supplemented with $5 \mu$ g erythromycin $\mathrm{ml}^{-1}$ when appropriate.

DNA manipulations. Plasmid DNA was isolated from E. coli and L. lactis by using the Concert rapid plasmid isolation kit (Gibco-BRL). For L. lactis this was preceded by a $30 \mathrm{~min}$ incubation at $37^{\circ} \mathrm{C}$ in solution G1 in the presence of $2 \mathrm{mg}$ lysozyme $\mathrm{ml}^{-1}$ and $10 \mathrm{U}$ mutanolysin $\mathrm{ml}^{-1}$ to obtain clear lysates. Restriction enzymes and T4 DNA ligase were purchased from Boehringer and used according to the suppliers' instructions. Oligonucleotides were synthesized using an Applied Biosystems 391 DNA synthesizer. The $\mathrm{CaCl}_{2}$ transformation method was used for E. coli (Dagert \& Ehrlich, 1979) whilst L. lactis was transformed by electrotransformation as described by Wells et al. (1993). DNA fragments generated by PCR were subcloned in pCR2.1-TOPO TA using the TOPO TA cloning system (Invitrogen) according to the manufacturer's instructions.

Propagation of Tuc2009. Propagation of phage was performed by growing the indicator strain to an $\mathrm{OD}_{600}$ of approximately $0 \cdot 2-0 \cdot 3$ at which point $\mathrm{CaCl}_{2}$ was added to a final concentration of $10 \mathrm{mM}$, prior to the addition of phage. Incubation was subsequently continued until lysis occurred.

Bacteriophage assays. Plaque assays were carried out as described by Lillehaug (1997). Briefly, M17 double-layer agar plates, containing $0.5 \%$ glucose, $0.5 \%$ glycine and $10 \mathrm{mM}$ $\mathrm{CaCl}_{2}$, were prepared with $1 \%$ agar for the bottom layer and $0.4 \%$ agar for the top layer. Media were sterilized by boiling for $5 \mathrm{~min}$ in a microwave oven. Plates contained approximately $30 \mathrm{ml} 1 \%$ agar and were overlaid with $2.5 \mathrm{ml} 0.4 \%$ agar, supplemented with $100 \mu \mathrm{l}$ indicator strain $\left(\mathrm{OD}_{600}=\right.$ $0 \cdot 6-0 \cdot 8)$ and appropriate dilutions of freshly prepared phage lysates.

Subcloning of pCIS3 and sequence analysis. Plasmid pCIS3 was isolated from an agarose gel and subjected to digestion with a number of endonucleases. A single linear DNA fragment was obtained upon digestion with the endonucleases EcoRI, BamHI and PstI. The latter was used for cloning of the plasmid into the Pst I site of pBluescript $\mathrm{SK}^{+}$, generating pBIS3. The plasmid was subcloned by ligation of a partial Sau $3 \mathrm{~A}$ digest with a BamHI digest of pBluescript $\mathrm{SK}^{+}$. The ligation mixture was used to transform E. coli XL-1 Blue and 
Table 1. Strains, plasmids and phage

\begin{tabular}{|c|c|c|}
\hline Strain, plasmid or phage & Relevant features & Source/reference \\
\hline \multicolumn{3}{|l|}{ Strains } \\
\hline \multicolumn{3}{|l|}{ L. lactis subsp. cremoris } \\
\hline UC509.9 & $\begin{array}{l}\text { Derivative of UC509 strain cured of prophage } \\
\text { Tuc2009, used as indicator strain }\end{array}$ & Costello (1988) \\
\hline UC509.93 & UC509.9-derived strain, cured of pCIS3 & This work \\
\hline UC509.935 & $\begin{array}{l}\text { UC509.9-derived strain, cured of pCIS3 and pCIS5, } \\
\text { Lac }^{-}\end{array}$ & This work \\
\hline IL1403 & $\begin{array}{l}\text { Plasmid-free strain, indicator strain for phage bIL66 } \\
\text { and } 952\end{array}$ & Chopin et al. (1984) \\
\hline \multicolumn{3}{|l|}{ E. coli } \\
\hline XL-1 Blue & 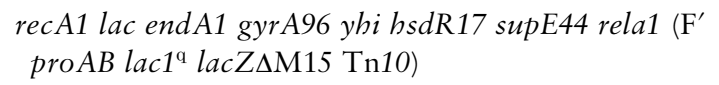 & Stratagene \\
\hline \multicolumn{3}{|l|}{ Plasmids } \\
\hline pCIS3 & $6 \cdot 1 \mathrm{~kb}$ plasmid from L. lactis UC509.9 & This work \\
\hline pBluescript SKII + & $\mathrm{Amp}^{\mathrm{r}}$, lac $Z \alpha$ complementation & Stratagene \\
\hline pBIS3 & $\begin{array}{l}\text { Amp } \\
\text { site }\end{array}$ & This work \\
\hline pGKV210 & $\begin{array}{l}\mathrm{Em}^{\mathrm{r}}, \mathrm{pWVO} 1 \text {-derived plasmid carrying the } \\
\text { erythromycin-resistance marker of pE194 }\end{array}$ & Van der Vossen et al. (1987) \\
\hline pCIS31.1 & $\begin{array}{l}\mathrm{Em}^{\mathrm{r}} \text {, pCIS3 carrying the erythromycin-resistance } \\
\text { gene of pGKV210 on a PstI-SmaI fragment from } \\
\text { pGKV210 }\end{array}$ & This work \\
\hline pFDi18 & $\begin{array}{l}\mathrm{Cm}^{\mathrm{r}} \text {, pCI305 (Hayes et al., 1991) derived, carrying } \\
\text { the nonsense suppressor supB }\end{array}$ & Dickely et al. (1995) \\
\hline \multicolumn{3}{|l|}{ Bacteriophages } \\
\hline Tuc2009 & Temperate phage, isolated from L. lactis UC509 & Arendt et al. (1994) \\
\hline 952 & Lytic phage for IL1403 & University College, Cork collection \\
\hline bIL66 & Lytic phage for IL1403 & Bidnenko et al. (1995) \\
\hline
\end{tabular}

transformants were selected on plates containing X-Gal. Plasmid DNA from individual white colonies was isolated, checked for the presence of inserts and used for sequence analysis that was performed with an Applied Biosystems 373A automated DNA sequencer. Assembly of sequences was done with the SEQMAN program of the DNASTAR software package. Database searches were performed with the programs BLASTP, BLASTN and TBLASTN (Altschul et al., 1997). Finally, oligonucleotides flanking the Pst I site were used to generate a PCR fragment using pCIS3 as a template. This fragment was sequenced in order to confirm that the PstI site was unique and not closely linked to another PstI site.

PCR. PCR amplifications were performed by using the mastermix supplied by Qiagen with a Gene Amp PCR system 2400 thermal cycler (Perkin-Elmer Cetus). To obtain reproducible results with colony PCR for L. lactis, $1 \mathrm{U}$ mutanolysin per reaction was added to the $\mathrm{PCR}$ mix. An initial incubation step of $15 \mathrm{~min}$ at $37^{\circ} \mathrm{C}$ prior to the normal PCR cycle was added to the program and found to be sufficient for reliable results. Addition of minor amounts of lysozyme did not improve the results, whereas the addition of lysozyme in excess of $100 \mathrm{ng} \mathrm{ml}^{-1}$ actually inhibited the PCR reactions.

Southern hybridizations. Southern transfers were carried out as described by Sambrook et al. (1989) using Hybond$\mathrm{N}+$ membranes (Amersham) as carrier. Probe labelling, hybridization and detection of complementary DNA were conducted using the ECL gene detection system (Amersham) as recommended by the manufacturer.

\section{RESULTS}

\section{Plasmid curing and identification of an R/M phenotype}

The prophage-cured strain L. lactis UC509.9 carries a total of six plasmids, named pCIS1 to pCIS6 (Fig. 1, lane 1). Introduction of the pCI305-derived plasmid pFDi18 (Dickely et al., 1995), which carries the nonsense suppressor supB and confers chloramphenicol resistance on UC509.9, appeared to be associated with the loss of pCIS3. It was found that phage propagated on this strain, designated UC509.93(pFDi18), infected L. lactis UC509.9 with an e.o.p. of $10^{-4}$. Phage isolated from individual plaques on L. lactis UC509.9 gave equal plaque counts on both L. lactis UC509.9 and UC509.93(pFDi18) (results not shown). To show that this phenotype, typical for $\mathrm{R} / \mathrm{M}$ systems, resulted from the loss of pCIS3 rather than the introduction of pFDi18, UC509.93(pFDi18) was cured of pFDi18 by continuous growth in the absence of antibiotic selection for over 100 generations. Samples were plated on GM17 and 


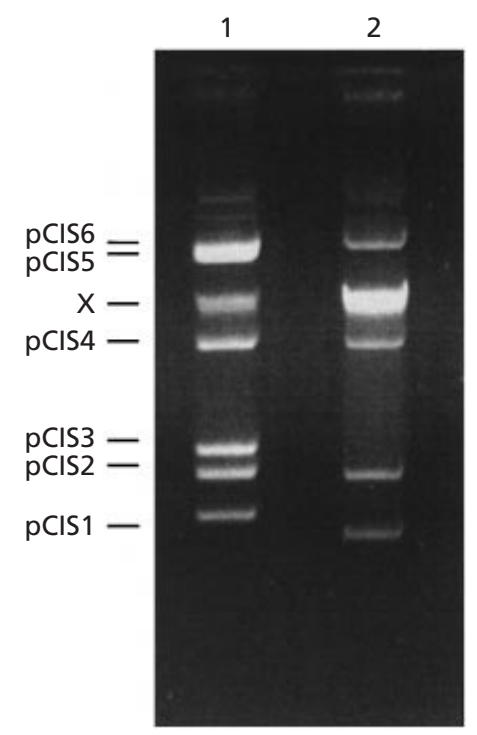

Fig. 1. Plasmid profiles of L. lactis UC509.9 (lane 1) and UC509.935 (lane 2). Plasmids are named pCIS1-CIS6 and their respective positions are indicated at the left of the panel. $X$, chromosomal DNA.

individual colonies were replica plated on chloramphenicol-containing plates to test for the loss of antibiotic resistance. Plasmid profiles of chloramphenicolsensitive colonies showed that these had indeed lost pFDi18.

Continuous subculturing of this strain in the presence of glucose in some cases also resulted in the loss of another plasmid, pCIS5. This strain, denoted L. lactis UC509.935 (Fig. 1, lane 2), was no longer capable of growing in media with lactose as the sole carbon source, indicating that pCIS5 encodes one or more lactose-metabolizing genes, a trait which is typically found to be linked to larger (> $20 \mathrm{~kb}$ ) plasmids (McKay, 1983).

As can be seen from Fig. 1, pCIS1 appears smaller when isolated from UC509.935 than when isolated from UC509.9. This is possibly due to some deletion event. Endonuclease treatment showed that pCIS1 from UC509.935 is approximately $100 \mathrm{bp}$ smaller than pCIS1 isolated from UC509.9.

\section{DNA sequence analysis}

The entire nucleotide sequence of pCIS3 was determined. It consists of $6159 \mathrm{bp}$ with a total $\mathrm{G}+\mathrm{C}$ content of $35.9 \mathrm{~mol} \%$. Four ORFs could be identified (Fig. 2, Table 2). The first ORF, designated rep, shows high similarity to a family of replication genes that are commonly found in lactococcal strains and encode the replication-initiation protein. The highest level of similarity was found to the rep gene of pCI305. Similar to other members of this family of replicons, rep is preceded by a $22 \mathrm{bp}$ sequence, repeated three and a half times (nt 314-390). This repeated region is $100 \%$ identical to that

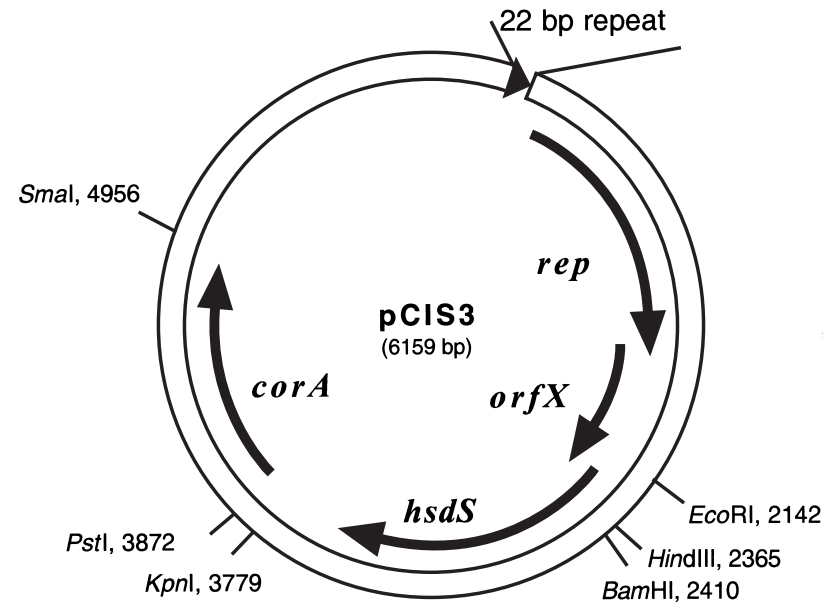

Fig. 2. Circular map of pCIS3. ORFs are indicated by solid arrows. The $22 \mathrm{bp}$ repeat refers to the iteron preceding the replication-initiation gene rep which is repeated three and a half times.

of pCI305. rep is followed by an ORF of unknown function, designated orf $X$. Directly downstream of orf X, a third ORF is found, which shows high levels of homology to $h s d S$ genes of type I R/M systems. Alignment of the deduced amino acid sequence of this gene with the $h s d S$-encoded proteins of other lactic acid bacteria clearly shows the conserved domains, separated by variable domains (Fig. 3a). The N-terminal constant region is repeated at the $3^{\prime}$ end of the middle region, while the conserved C-terminal domain is repeated at the $5^{\prime}$ end of the middle region. rep, orf $X$ and $h s d S$ are organized in an operon-like structure with the last two codon sequences of rep overlapping the first two of orf $X$ and the last three codon sequences of orf $X$ overlapping the first three of $h s d S$. No putative promoter sequences could be identified directly upstream of orf $X$ and $h s d S$. Each is, however, preceded by near-consensus ribosomebinding sites.

pCIS3 encodes a fourth ORF, designated $\operatorname{cor} A$, whose gene products display significant similarity to a ubiquitous class of magnesium transporter proteins with affinity for cobalt and nickel.

\section{Natural stacking of $h s d S$ genes in L. lactis UC509.9}

Recombination between the variable domains of different $h s d S$ genes in a single strain is likely to play a role in ensuring continued dynamics in phage defence. In addition, plasmids can be mobilized between strains and if the conjugated plasmid carrying an $h s d S$ gene is introduced into a strain that already carries a different $h s d S$ locus, the unique structure of these genes allows recombination to occur, resulting in novel hsdS genes with altered specificities (Fuller-Pace et al., 1984). This also implies that one strain could carry two or more hsdS genes. To determine if this is the case in L. lactis UC509.9, two oligonucleotides were designed, based on 
Table 2. Co-ordinates of identified ORFs on pCIS3

Genes with the highest level of identity as found in the database are indicated as well as the level of identity which is given as the $E$ value. The closer the $E$ value is to 0 , the higher the level of homology.

\begin{tabular}{|lllll|}
\hline Gene & Co-ordinates & Homology to & E value & Reference \\
\hline rep & $503-1663$ & pCI305 repA & $0 \cdot 0$ & Hayes et al. (1991) \\
orfX & $1656-2288$ & pIL7 orfX & $3 \cdot 1 \times 10^{-79}$ & Seegers et al. (1994) \\
hsdS & $2276-3508$ & pIL7 hsdS & $4 \cdot 4 \times 10^{-127}$ & Schouler et al. (1998a) \\
corA & $3932-4843$ & Methanococcus jannaschii & $2 \cdot 1 \times 10^{-8}$ & Bult et al. (1996) \\
& & corA & & \\
\hline
\end{tabular}

(a)

PCIS3

pCI65st

PIL2614

pND861

PIL103

PNZ 4000

pCIS 3

pCI65st

pIL7

pIL2614

pND861

PIL103

IL 1403

PNZ4000

pCIS 3

pCI65st

pIL7

pIL2614

pND861

pIL103

PNZ4000

pCIS 3

pCI65st
pIL7

PIL2614

pND861

pIL103

IL1 103

IL1403

MAKIDDSVKKKVPELRFPGFTDDWEERKLGS-LTTVVR--GASPRPIQDPKWFDKESDIGWLRIADVTEQNGRIYHLEQHIS---KLGQEK--TRVLTEPHLLLSIAAT----VGKPVVN MAKIDDSVKKEVPELRFKGFTDDWEERKLGE-LANIVG--GGTPSTSNPEYWDG---DI DWYAPAEIGE-QSYVSKSKKTIT---ELGLKNSSARILPVGTVLFTSRAG----IGN-TAI MAKIDDSVKKKVPELRFKGFTNDWEERKLGE-LSNIVG--GGTPSTSNPEYWDG---DIDWYAPAEIGE-QSYVSKSKKTIT---ELGLKKSSARILPVGTVLFTSRAG----IGN-TAI -----MMSKKSPQLRFEGFTDDWEERKFGE----VWK--KSSERNLN---------LEYSPKQVLSVAQMKLNPSNRNEQ---DDYMKT--YNVLHKGDIAFEGNKSKSFAFGRFVLD ------MSKKSPQLRFEGFTDDWEKRKLKD---FTIK----TGKKNS----.---EGEDHPAYSVSNKLGLVSQTKQFDGSRLDFLDKT-AYKFVNQGEFAYNPARIN---VGS--IA MAKIDDSVKKRVPELRFPGFTNDWEERKFFESIAST IDFRGRT PKKLGMD-WSD---SGYLALSALNVK-NGYIDPLADAHYGDEKLYRKWMSGRELKKGQVLFTTEAP-----MGN-VAQ MAKIDDSUKKRVEPLREPGETNDWEERKEEESIA MAKIDDSVKKKVPELRFPGFTDDWEERKLSEGTSKIGDGLHGTPNYSD----NG----DVFFINGNNLVNGKIVITKETKLVT---ESNOSK-DDKLLNMDTILMS INGT-----IGN-LAW

YVKTG---VHDGFLIFLN--PTFER--EFMFQWLEMFRPKWQKYGQPGSQVN--LNSELVRNQEI-VLPNYK-EQQKIGSFFKQLDNTITLHQRKLDLLKEQKKGYLQKMFPKNGAKVPE LAKEA--TTNQGFQSI VPDQNKLDS--YFI FSRTNELKRYGEVTGAGST FVE--VSGKQMSKMSI-MVPELS-EQQRI GSFFKQLDETITLHQRKLDLLKEQKKGFLQKMFPKNGAKVP LAKEA--TTNQGFQS IVPDQNKLDS--YFIFSRTNELKRYGEVTGAGSTFVE--VSGKQMSKMSI-MVPELS-EQQKI GNFFKELDNTI IALHQRKLDLLKEOKKGYLOKMFPKNGAKVPE DLQDG--IVSHVFYVYRP-ICKMDTDFMIVY INNESVMKYLIVKATTKTLMMTTLNTKDIVKPKL-NLPSLE-EQQKIGSFFKQLDATIALHQRKLDLLKEQKKGYFQKMFPKNGAKVP FNDLGKTVIVSSLYVVLKISDKLDNEYILQFIKSIKFIEEVKRNTEGSVREY--LFFDNFKNIKFPYIKNLE-EQQKIGSFFKQLDNTITLHQRKLDLLKEQKKGYLQKMFPKNGAKVP VPDDNGY I LSQRTVAFETKEDMMTNDFLAVLLKSPLVFNNLSALSSGGTAKG--VSQKSLKGLSI-TVPLDIDEQQKIGSFFKHLDDTIALHQRKLDLLKEQKKGYLQKMFPKNGAKVP VPDNNGY I LNQRAVAFKSLQETDDN-FFAQLLRSP IVQNTLKASSSGGTAKG--IGMKEFAKLNA-RVPETHEEQRKIGLFFKQLDDTIVLHQRKLDLLKEQKKGYLQKMFPKNGSKI PE YNNER--VMLGKSAAYLTVSN-FDKKFIFSYLQTST I KNYFINNLTGTTIKN--LGLKTIRDTTL-FVPTLE-EQQKIGSFFKQIDDTIALHQRKLDLLKEQKKGYLQKMFPKNGAKVPE

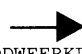

LRFAGFADDWEFRISS-MTNYKNG--KSHEDKQSTSGKLELINLNSISISGG--LKHSGKFIDEAD--DTLOKDDLVMILSDVG------HGDLLGRVALI PED--DRFVLNQRVALLRP (1)

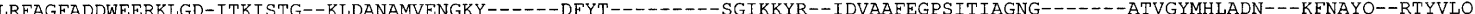
L URFA LRFAGFVDDEQRKLGEMLVNLEAG LRAGEADDWERKLGD-IAPLRGG-YAFKSKERK

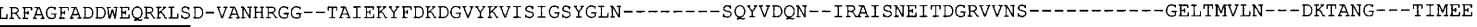

NTTADPQFLFSYINAH--QYYFKAQGAGMS--QLNISKGSVENFI SFVP-I IEEQKKIGSFFKQLDETIALHQRKLDLLKE-QKKGFLQKMFVQNKLDSYFIFSRT-NEL-KRYGEVTGAGST--FVEVSGKQMSKMS IMVP-ELSEQQKIGLFFKHLDDTITFHQRKLDLLKE-QKKGFLQKMFI EFLVDRSFIFSEIGNKL-PKKI KQEARTGN--I PYIVMDMLTELKLSI PQNNSEQQR I GSFFKQLDDTIALHQRKLAFVERTENTGFLQKMFV-VNYIDSI FLALT I SNGSQQKEMSKRAQGKS--VVHLHNSDLKQVNILYP-KLGEQQKIGS FFKQLDNTIVLHQRKLDFLKE-QKKGFLQKMFV-AGNFS PEWLIQS INI AANIKK I RDLATGTSGSMKNISKKSMLDL I INVP-TLEEQQK IGSFFKQLDDVIALHQRKLDLLKE-QKKGFLQKMFV---..VDY IDYGFIST IVRSEL LMMOLESVLVSGA--QPNVSSKEI DSFN FMI PI LVQEQOK IGSFFKQLDDT IALHQRKLDLLKE-OKKGFLQKMFV-_SKFLDRNFTLQLLEAD--KARLLSSTNGST--MI HVTKGDMESKIVSI PN-IDEQKQI GSFFKQLDNT ITLHQRKLDLLKE-QKKGFLQKMFHLTNLGAFTMET IQKYLKI IVESNYLHQ

\section{(b)}

3 DWEERKLGELTTSFSGGTPSAGNSSYYKGDIPFIRSGEINSDKTELFLTEAGLKSSSAKMVSVGDILY

V4 DWEERKLSEITDFHKQGFYTKESYNENKKYYLLRGTDMTSNKLILKDTPKINASEKDYEDFKVLKDDF

V5 DWEERKLGELANIVGGGTPSTSNPEYWDGDIDWYAPAEIGEQSYVSKSKKTITELGLKNSSARILPVG

V3 ALYGATSGEVGISOINGAINOAILAIKPCDGYNSHFLMOWLKLKKOKI IDOYLQGGOGNLSGSIVKNL

V4 LIVRSGTVGTYAIVKSDITAIFGSYLINERFNQS IVLNEFFGLFYQSSLFKSQLNKIIQKSSNVNINA

V5 TVLFTSRAGIGNTAILAKEATTNQGEQSIVPDQNKLDSYFIFSRTNELKRYGEVTGAGSTFVEVSGKQ

V3 VLKV------PNEEEOKKIGAFFKOLDDTITLHORK

V4 ENIKSTNIKFPTIEEQQKIGAFFQSIDDTIALHQRK

V5 MSKMSIMVP--ELSEQQKIGSFFKQLDETITLHQRK

$\mathrm{SC} 2$

Fig. 3. (a) Alignment of the deduced amino acid sequence of pCIS3 with those of pCI65st (GenBank accession no. AF034786), pIL7 (AF013596), pIL2614 (U90222), pND861 (AF034786), plL103 (AF013595), the chromosomal hsdS gene from L. lactis IL1403 (AF013165) and pNZ4000 (AF036485). The region corresponding to the conserved $5^{\prime}$ end of each $h s d S$ domain is underlined with a thin line. The region corresponding to the conserved $3^{\prime}$ end of each hsdS domain is underlined with a thick line. Rightward pointing arrows indicate the relative positions of SC1. Leftward pointing arrows indicate the relative positions of SC2. (b) Alignment of deduced amino acid sequences of fragments that were obtained by PCR using primers SC1 and SC2, with total DNA of L. lactis UC509.935 as target. The locations of SC1 and SC2 are underlined. Obtained fragments were of the expected length and encoded an ORF in one of the frames over the full length of the determined sequence. 
(a)

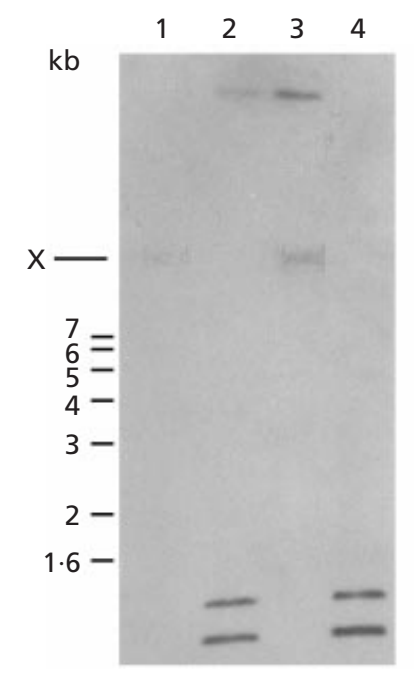

(b)

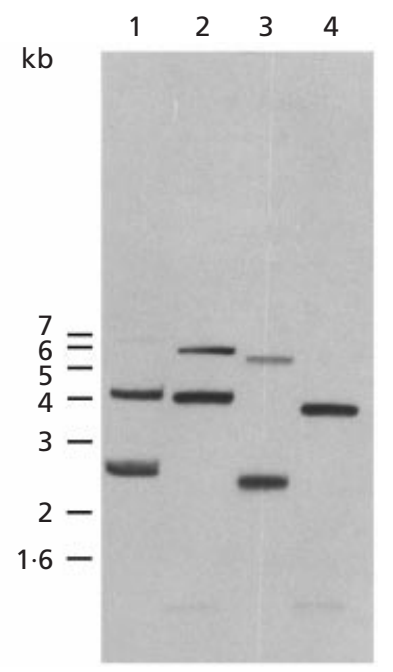

Fig. 4. Southern analysis of total DNA from UC509.9 and UC509.93 either uncut (lanes 1 and 3, respectively) or digested with HindIII (lanes 2 and 4, respectively). $X$ indicates the position of chromosomal DNA. (a) Probe DNA hsdM, obtained by PCR using oligonucleotides M5 and M6 with total genomic DNA of UC509.9 as template. (b) Probe DNA hsdS, obtained by PCR using oligonucleotides SC1 and SC2 with total genomic DNA of UC509.9 as template. The faint band at the bottom of lanes 2 and 4 in (b) corresponds to the upper of the bottom two bands in lanes 2 and 4 of (a). The signal for the uncut chromosomal DNA in (b) was not strong enough to be visible under the conditions employed. Bands at the top of lanes 2 and 3 in (a) result from DNA in the wells that failed to enter the gel. The additional bands in lanes 1 and 3 in (b) between 6 and $7 \mathrm{~kb}$ represent open circular plasmid DNA of pCl1.

the conserved domains that flank the variable domains of $h s d S$ genes (SC1, $5^{\prime}$-GATTGGGAAGAGCGTAAGTT-3' and SC2, 5'-AACTTACGCTGATGAAGA-3'). These were used for PCR amplification of total DNA isolated from UC509.935. A product of the expected size was obtained and subcloned into pCR2.1-TOPO TA. Eight individual colonies were checked for inserts and used for sequence analysis. Three variable domains, designated V3, V4 and V5, differing from those of pCIS3, could thus be identified, indicating the presence of at least two additional $h s d S$ genes in this strain. The alignment of the protein products specified by V3, V4 and V5 is presented in Fig. 3(b). The combined PCR products were used for Southern analysis. This confirmed the presence of two additional $h s d S$ genes, one of which was found to be chromosomally located, whilst the other was located on pCIS1, the smallest plasmid present in UC509.9 (approx. 4 kb; Fig. 4b, lane 4).

\section{The $h s d M$ subunit of UC509.9 is similar to $h s d M$ of L. lactis IL1403}

Schouler et al. (1998b) designed oligonucleotides (designated M3, M4, M5 and M6) that were based on conserved sequences within a number of $h s d M$ genes.

Table 3. Effect of the HsdS subunit of pCIS31.1 on the e.o.p. of phage Tuc2009 propagated on UC509.93, and phages 952 and bIL66 propagated on IL1403

NA, not applicable.

\begin{tabular}{|lccc|}
\hline Indicator strain & \multicolumn{3}{c|}{ Phage } \\
\cline { 2 - 4 } & Tuc2009 & $\mathbf{9 5 2}$ & bIL66 \\
\hline UC509.9 & $2 \cdot 3 \times 10^{-4}$ & NA & NA \\
UC509.93 & 1 & NA & NA \\
UC509.93(pCIS31.1) & $2 \cdot 5 \times 10^{-4}$ & NA & NA \\
IL1403 & NA & 1 & 1 \\
IL1403(pCIS31.1) & NA & $1 \cdot 4 \times 10^{-1}$ & $0 \cdot 9 \times 10^{-1}$ \\
\hline
\end{tabular}

Identical oligonucleotides were used for PCR amplification experiments on total DNA from UC509.9 in order to verify the presence of an hsdM subunit. A fragment of approximately $650 \mathrm{bp}$ was obtained with oligonucleotides M5 and M6. The nucleotide sequence of this fragment was determined and shown to be nearly identical to the nucleotide sequence of a corresponding fragment of the $h s d M$ gene of L. lactis IL1403 (nucleotide accession number AF013165). Southern hybridization experiments with this fragment showed that it was chromosomally located in UC509.9 (Fig. 4a, lanes 1 and 3).

To determine the orientation of the chromosomally encoded $h s d S$ gene with respect to the $h s d M$ gene, PCR reactions were performed with several combinations of the oligonucleotides M5, M6, SC1 and SC2. A product with a size of approximately $1.3 \mathrm{~kb}$ was obtained with the combination of M5 and SC2. All other combinations with the $\mathrm{M}$ and SC oligonucleotides failed to give a product. This indicates that the $h s d S$ gene is located directly downstream of the $h s d M$ gene in an orientation similar to that in L. lactis IL1403. The close proximity of $h s d M$ to $h s d S$ on the chromosome was confirmed by Southern hybridization where a common band of $1.2 \mathrm{~kb}$ was observed when either part of the $h s d M$ gene or a combination of variable domains from all $h s d S$ genes was used as a probe (Fig. $4 \mathrm{a}$ and $4 \mathrm{~b}$, lanes 2 and 4 , respectively).

\section{Effectiveness of HsdS subunits}

The effect of the HsdS subunit of pCIS3 on the e.o.p. of phage Tuc2009 on UC509.9 and phages bIL66 and 952 on IL1403 was studied. For this purpose pCIS3 was genetically marked with the erythromycin-resistance gene of pGKV210 to create pCIS31.1 (see Methods). This plasmid was introduced into L. lactis strains UC509.93 and IL1403. Phage was then isolated from UC509.93 or IL1403 and used to infect both strains in the presence or absence of pCIS31.1 (Table 3). Whereas the presence of pCIS31.1 resulted in a $10^{4}$-fold decrease in the e.o.p. for Tuc2009 on UC509.93, this effect was markedly less (only a 10-fold decrease) for bIL66 and 


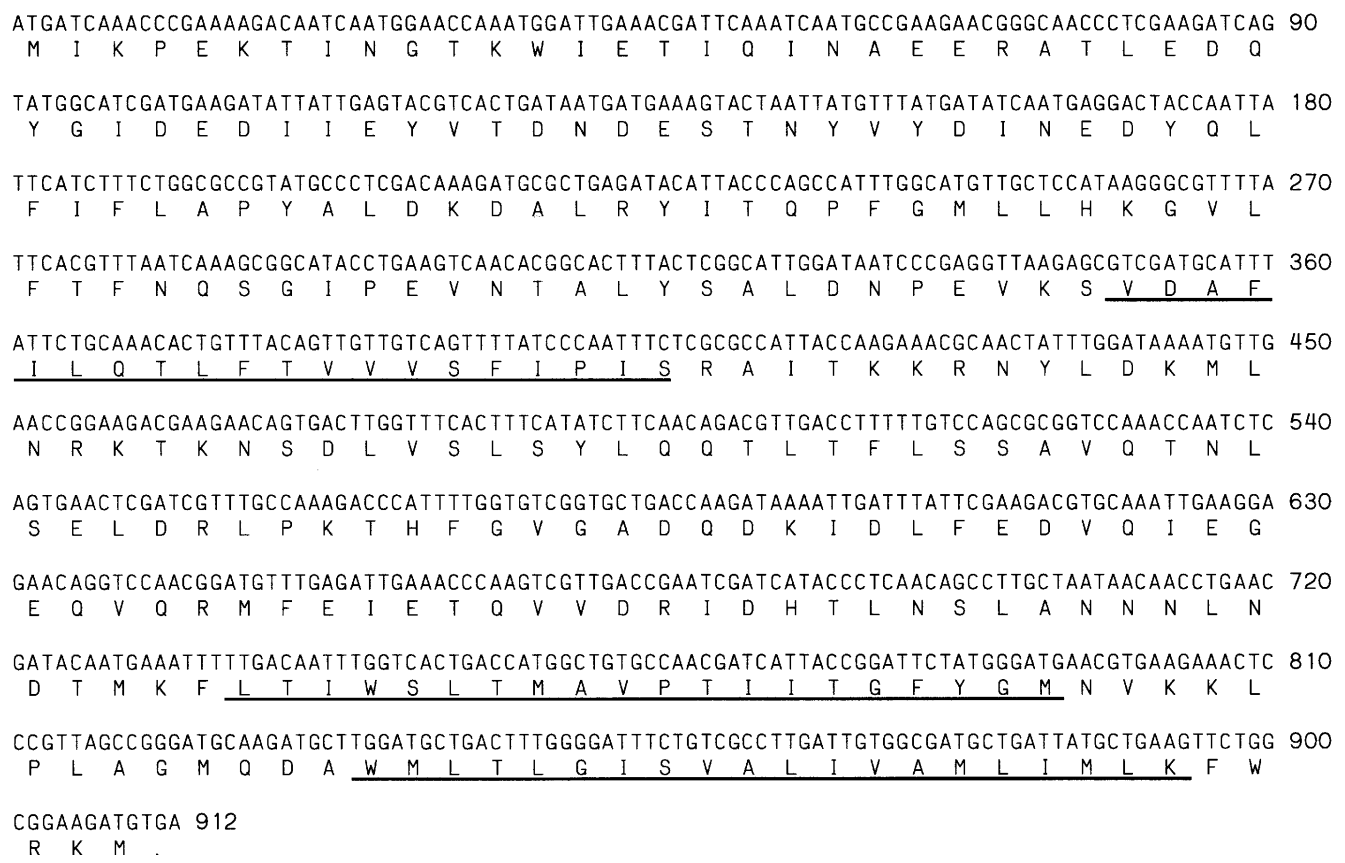

Fig. 5. Nucleotide sequence and deduced amino acid sequence of CorA. Three transmembrane domains were predicted by using the membrane domain prediction program TopPred2 (von Heijne, 1992; http://www.embl-heidelberg.de/ $\sim$ doerks/Package5.html), and are underlined in the sequence.

952 on IL1403. These values for IL1403 were similar to those observed by Schouler et al. (1998b) with the hsdS genes from pIL7 and pIL261 in conjunction with phage bIL67.

e.o.p. values, comparable to those obtained with the hsdS genes from pCIS31.1 and pIL7, were obtained when the $h s d S$ gene encoded by pCI65st (O'Sullivan et al., 1999) was used in UC509.93 and IL1403 (E. Stanley, unpublished results).

\section{Absence of corA results in increased cobalt resistance}

ORF4 of pCIS3 encodes a protein with similarity to CorA proteins identified in many prokaryotes (Kehres et al., 1998), where they function as the dominant $\mathrm{Mg}^{2+}$ uptake system. ORF4 is similar in size to other corA genes and its deduced protein product contains three putative transmembrane domains (Fig. 5). To assess the function of $\operatorname{cor} A$, its effect on the cobalt tolerance of the host strain was determined. For this purpose, both UC509.93 and UC509.9 were streaked on plates with increasing amounts of $\mathrm{CoCl}_{2}$. UC509.93 (lacking pCIS3) was capable of growing at concentrations up to $5 \mathrm{mM}$ $\mathrm{CoCl}_{2}$, whereas UC509.9 could only grow to a maximum of $1 \mathrm{mM} \mathrm{CoCl}{ }_{2}$ (Fig. 6). Introduction of pCIS31.1, from which $\operatorname{cor} A$ was deleted (see Methods), into UC509.93 restored phage resistance, but failed to increase cobalt resistance.

\section{DISCUSSION}

While creating a nonsense suppressor strain of the lactococcal strain UC509.9 by supplying a suppressor gene on a plasmid, it became apparent that phage isolated from the nonsense suppressor strain showed a marked decrease in the e.o.p. when used to infect the original host. However, the e.o.p. of phage that was reisolated from this original host reverted to a value of $1 \cdot 0$, which is typical for $\mathrm{R} / \mathrm{M}$ systems. Comparison of plasmid profiles showed that this $\mathrm{R} / \mathrm{M}$ phenotype could be attributed to the presence or absence of a single $6.2 \mathrm{~kb}$ plasmid. Nucleotide sequence analysis of this plasmid, denoted pCIS3, revealed the presence of an $h s d S$ gene of type I R/M systems. Type I R/M systems are widespread among prokaryotes, but have only recently been identified in lactococci (Schouler et al., 1998a). Using oligonucleotides based on conserved regions within hsdM genes (Schouler et al., 1998b), it was also possible to identify an $h s d M$ gene, similar to that of IL1403, on the chromosome of UC509.9. Furthermore, by using oligonucleotides based on the conserved domains of $h s d S$ genes in PCR amplification reactions, it was possible to demonstrate that at least two additional $h s d S$ genes were located in L. lactis UC509.9. Southern analysis confirmed the presence of a total of three $h s d S$ genes, one on the chromosome and two on small plasmids.

The presence of mobilization functions on lactococcal plasmids allows for transfer of plasmids (and the traits they encode) between different strains. When a plasmid that carries an $h s d S$ gene is transferred to a strain that 


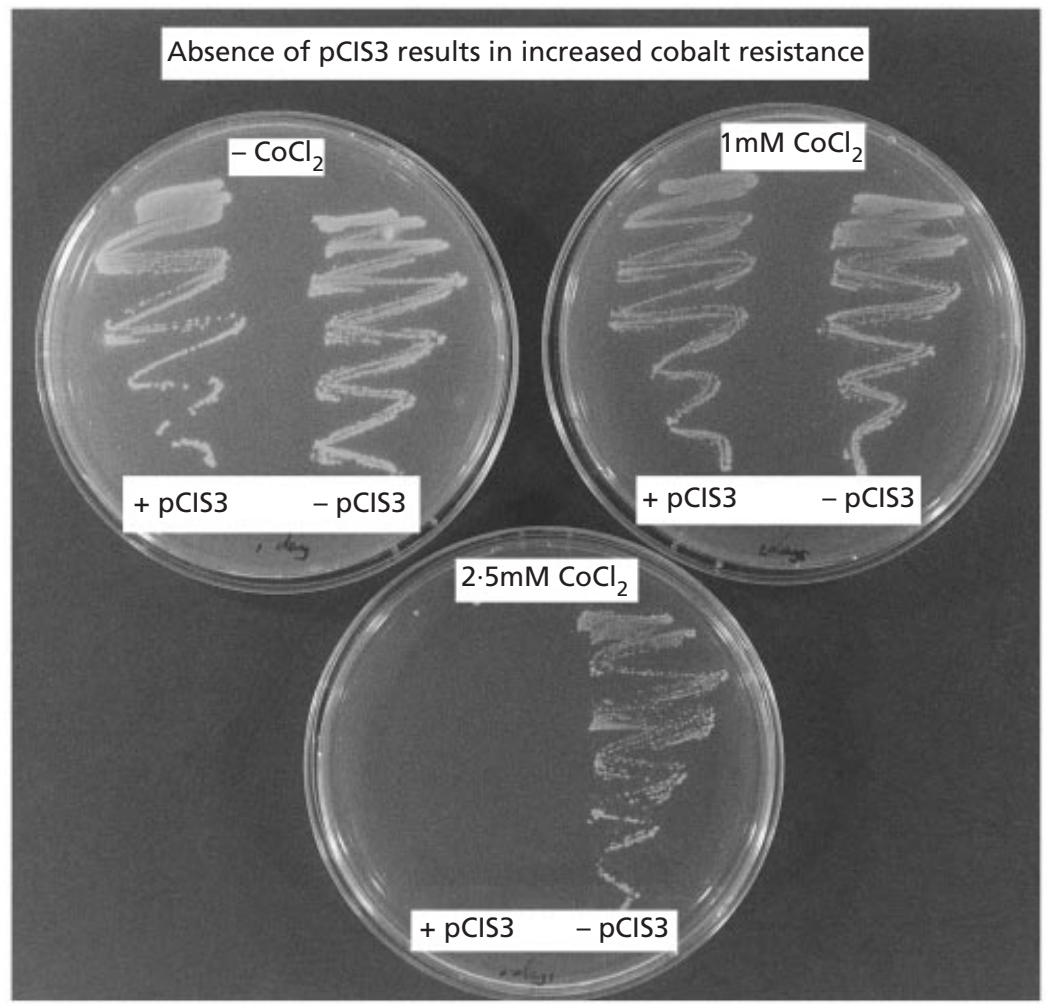

Fig. 6. Effect of presence or absence of CorA on cobalt resistance of the $L$. lactis host. Cells that carry pCIS3 cannot grow at cobalt concentrations in excess of $1 \mathrm{mM}$.

already carries such a gene, crossover events can occur, resulting in novel HsdS subunits with altered specificities. It can be envisaged that it is advantageous for a strain to carry more than one copy of the $h s d S$ genes in order to achieve a high level of variation, resulting in increased phage resistance.

PCR analysis indicated that the chromosomally located $h s d S$ gene lies downstream of the $h s d M$ gene in an orientation similar to that found for IL1403 (Schouler et al., 1998b). Based on the typical organization of type I $\mathrm{R} / \mathrm{M}$ systems found in lactococci to date, it can be expected that the $h s d R$ gene is located upstream of hsdM.

The effectiveness of two hsdS genes was evaluated for strains UC509.9 and IL1403. The effect on the e.o.p. of the genes that were tested was significantly greater in the UC509.9 host than in IL1403. The values that were obtained with pCIS3 and pCI65st for IL1403 were similar to those observed by Schouler et al. (1998a) for pIL7. Since the $h s d M$ genes of IL1403 and UC509.9 are nearly identical, it can be speculated that this difference in effectiveness could be related to the activity of HsdR. It can not, however, be excluded that phage Tuc2009 has more recognition sites for the pCIS3 and pCI65st subunits than bIL66 and phage 952 .

Three other genes were identified on pCIS3. The rep gene, encoding the replication-initiation protein, is located on a large family of theta replicating plasmids that is very common in lactococci (Seegers et al., 1994).
A $22 \mathrm{bp}$ sequence, repeated three and a half times, preceding this gene is thought to be the major compatibility factor (Foley et al., 1996; Gravesen et al., 1997). Indeed, comparison of this sequence from pCIS3 with sequences in the nucleotide database revealed that this region was $100 \%$ identical to that of pCI305 (Hayes et al., 1991). This latter plasmid was used for the construction of pFDi18, which carries the $\operatorname{supB}$ gene (Dickely et al., 1995), which explains why pCIS3 was lost from the strain when pFDi18 was introduced and provides further evidence for the role of the repeated fragment in compatibility.

The first codons of the second gene, named orf $X$, overlap the last codons of rep. Similar genes are found in most plasmids of this family. To date no function has been attributed to this gene.

The amino acid sequence of the fourth gene that could be identified showed similarity to a group of magnesiumtransporter proteins, commonly indicated as CorA. These genes have been shown to be ubiquitous in eubacteria and to encode their dominant $\mathrm{Mg}^{2+}$-uptake system (Smith \& Maguire, 1998). Loss of the plasmid resulted in an increase in cobalt resistance, indicating it has a similar function in UC509.9. However, the absence of $\operatorname{cor} A$ did not result in any other visible effects on growth under the conditions used. Possible explanations for this could be the presence of another corA gene on the chromosome or the presence of additional $\mathrm{Mg}^{2+}$ transporter proteins. To our knowledge this is the first example of such a gene located on a plasmid in bacteria. 


\section{ACKNOWLEDGEMENTS}

We thank Aina Healy and Sinead Geary for their contributions in oligonucleotide synthesis and sequence analysis and Liam Burgess for photographic work. We also thank Eric Johanson for supplying plasmid pFDi18. This work was sponsored by Bio Research Ireland.

\section{REFERENCES}

Allison, G. E. \& Klaenhammer, T. R. (1998). Phage resistance mechanisms in lactic acid bacteria. Int Dairy J 8, 207-226.

Altschul, S. F., Madden, T. L., Schäffer, A. A., Zhang, J., Zhang, Z., Miller, W. \& Lipman, D. J. (1997). Gapped BLAST and PSI-BLAST : a new generation of protein database search program. Nucleic Acid Res 25, 3389-3402.

Arendt, E. K., Daly, C., Fitzgerald, G. F. \& van de Guchte, M. (1994). Molecular characterization of lactococcal bacteriophage Tuc2009 and identification and analysis of genes encoding lysin, a putative holin, and two structural proteins. Appl Environ Microbiol 60, 1875-1883.

Bidnenko, E., Ehrlich, D. \& Chopin, M. C. (1995). Phage operon involved in sensitivity to the Lactococcus lactis abortive infection mechanism AbiD1. J Bacteriol 177, 3824-3829.

Bult, C. J., White, O., Olsen, G. J. \& 20 other authors (1996). Complete genome sequence of the methanogenic archaeon, Methanococcus jannaschii. Science 273, 1058-1073.

Chopin, A., Chopin, M. C., Moillo-Bat, A. \& Langella, P. (1984). Two plasmid-determined restriction and modification systems in Streptococcus lactis. Plasmid 11, 260-263.

Costello, V. A. (1988). Characterization of bacteriophage-host interactions in Streptococcus cremoris UC503 and related lactic streptococci. PhD thesis, National University of Ireland, University College Cork, Ireland.

Dagert, M. \& Ehrlich, S. D. (1979). Prolonged incubation in calcium chloride improves competence of Escherichia coli cells. Gene 6, 23-28.

Davis, R., van der Lelie, D., Mereenier, A., Daly, C. \& Fitzgerald, G. F. (1993). ScrFI restriction-modification system of Lactococcus lactis subsp. cremoris UC503: cloning and characterization of two ScrFI methylase genes. Appl Environ Microbiol 59, 777-785.

Dickely, F., Nilsson, D., Hansen, E. B. \& Johansen, E. (1995). Isolation of Lactococcus lactis nonsense suppressors and construction of a food-grade cloning vector. Mol Microbiol 15, 839-847.

Foley, S., Bron, S., Venema, G., Daly, C. \& Fitzgerald, G. F. (1996). Molecular analysis of the replication origin of the Lactococcus lactis plasmid pCJ305. Plasmid 36, 125-141.

Forde, A., Daly, C. \& Fitzgerald, G. F. (1999). Identification of four phage resistance plasmids from Lactococcus lactis subsp. cremoris HO2. Appl Environ Microbiol 65, 1540-1547.

Fuller-Pace, F. V. \& Murray, N. E. (1986). Two DNA recognition domains of the specificity polypeptides of a family of type 1 restriction enzymes. Proc Natl Acad Sci USA 83, 9368-9372.

Fuller-Pace, F. V., Bullas, L. R., Delius, H. \& Murray, N. E. (1984). Genetic recombination can generate altered restriction specificity. Proc Natl Acad Sci USA 81, 6095-6099.

Garvey, P., van Sinderen, D., Twomey, D. P., Hill, C. \& Fitzgerald, G. F. (1995). Molecular genetics of bacteriophages and natural phage defense systems in the genus Lactococcus. Int Dairy J 5, 905-947.
Garvey, P., Hill, C. \& Fitzgerald, G. F. (1996). The lactococcal plasmid pNP40 encodes a third bacteriophage resistance mechanism, one which affects phage DNA penetration. Appl Environ Microbiol 62, 676-679.

Gravesen, A., von Wright, A., Josephsen, J. \& Vogensen, F. K. (1997). Replication regions of two pairs of incompatible lactococcal theta-replicating plasmids. Plasmid 38, 115-127.

Hayes, F., Vos, P., Fitzgerald, G. F., de Vos, W. M. \& Daly, C. (1991). Molecular organization of the minimal replicon of novel, narrow-host-range, lactococcal plasmid pCI305. Plasmid 25, $16-26$.

von Heijne, G. (1992). Membrane protein structure prediction, hydrophobicity analysis and the positive-inside rule. J Mol Biol 225, 487-494.

Kehres, D. G., Lawyer, C. H. \& Maguire, M. E. (1998). The CorA magnesium transporter gene family. Microb Comp Genomics 3, 151-169.

Lillehaug, D. (1997). An improved plaque assay for poor plaqueproducing temperate lactococcal bacteriophages. J Appl Microbiol 83, 85-90.

McKay, L. L. (1983). Functional properties of plasmids in lactic streptococci. Antonie Leeuwenhoek 49, 259-274.

O'Sullivan, D. J., Zagula, K. \& Klaenhammer, T. R. (1995). In vivo restriction by LlaI is encoded by three genes, arranged in an operon with llaIM, on the conjugative Lactococcus plasmid pTR2030. J Bacteriol 177, 134-143.

O'Sullivan, T., van Sinderen, D. \& Fitzgerald, G. (1999). Structural and functional analysis of pCI65st, a $6.5 \mathrm{~kb}$ plasmid from Streptococcus thermophilus NDI-6. Microbiology 145, 127-134.

Sambrook, J., Fritsch, E. F. \& Maniatis, T. (1989). Molecular Cloning: a Laboratory Manual, 2nd edn. Cold Spring Harbor, NY : Cold Spring Harbor Laboratory.

Schouler, C., Clier, F., Lerayer, A. L., Ehrlich, S. D. \& Chopin, M. C. (1998a). A type IC restriction-modification system in Lactococcus lactis. J Bacteriol 180, 407-411.

Schouler, C., Gautier, M., Ehrlich, S. D. \& Chopin, M. C. (1998b). Combinational variation of restriction modification specificities in Lactococcus lactis. Mol Microbiol 28, 169-178.

Seegers, J. F., Bron, S., Franke, C. M., Venema, G. \& Kiewiet, R. (1994). The majority of lactococcal plasmids carry a highly related replicon. Microbiology 140, 1291-1300.

Smith, R. L. \& Maguire, M. E. (1998). Microbial magnesium transport: unusual transporters searching for identity. Mol Microbiol 28, 217-226.

Su, P., Im, H., Hsieh, H., Kang, A. S. \& Dunn, N. W. (1999). LlaFI, a type III restriction and modification system in Lactococcus lactis. Appl Environ Microbiol 65, 686-693.

Van der Vossen, J. M., van der Lelie, D. \& Venema, G. (1987). Isolation and characterization of Streptococcus cremoris Wg2specific promoters. Appl Environ Microbiol 53, 2452-2457.

Wells, J. M., Wilson, P. W. \& Le Page, R. W. (1993). Improved cloning vectors and transformation procedure for Lactococcus lactis. J Appl Bacteriol 74, 629-636.

Yuan, R. (1981). Structure and mechanism of multifunctional restriction endonucleases. Annu Rev Biochem 80, 285-315.

Received 17 June 1999; revised 19 October 1999; accepted 2 November 1999. 